УДК 622.06

\title{
ОЦЕНКА ЭФФЕКТИВНОСТИ ПАРЛИФТНОЙ ДОБЫЧИ ФЛЮИДА НА МУТНОВСКОМ ГЕОТЕРМАЛЬНОМ МЕСТОРОЖДЕНИИ (КАМЧАТКА) ПРИ РАЗРАБОТКЕ ГЛУБОКИХ ГОРИЗОНТОВ
}

\author{
Шулюпин Александр Николаевич1, \\ ans714@mail.ru
}

\author{
Любин Алексей Анатольевич², \\ Lyubin-AA@kamenergo.ru \\ Чернев Иван Иванович², \\ Chernev-II@kamenergo.ru \\ 1 Институт горного дела ДВО РАН, \\ Россия, 680000, г. Хабаровск, ул. Тургенева, 51. \\ 2 Филиал ПАО «Камчатскэнерго» Возобновляемая энергетика, \\ Россия, 680009, г. Петропавловск-Камчатский, ул. Ак. Королева, 60.
}

\begin{abstract}
Актуальность исследования обусловлена необходимостью расширения ресурсной базы Мутновского геотермального месторождения (Камчатка) для восполнения дефицита теплоносителя на действующих ГеоЭС и наращивания мощности станций.

Цель: оценить эфрфективность парлифтннй добычи теплоносителя на Мутновском месторождении при переходе к освоению глубоких горизонтов (скважинами глубиной 3 и 4 км при существующей глубине освоения 2 км).

Методы: теоретическое обоснование показателя эфффективности парлифтной добычи геотермального фрлюида; математическое моделирование течения в добычной парлифртной скважине при существующей типовой конструкции (глубиной 2 км), а также в планируемых к бурению скважинах глубиной 3 и 4 км; анализ результатов моделирования.

Результаты. Обосновано использование в качестве показателя эфффективности парлифта максимальной депрессии в пласте, которую может обеспечить парлифтнная технология добычи; установлено, что освоение более глубоких горизонтов Мутновского месторождения скважинами до 3 км, при существующей глубине освоения до 2 км, позволит существенно повысить эффрективность парлифтнной добычи, увеличив максимальную депрессию в пласте, создаваемую добычными скважинами, примерно в два раза; установлено, что увеличение глубины освоения Мутновского месторождения до 4 км целесообразно в случае наличия роста температуры резервуара на планируемой к освоению глубине, так, в случае увеличения температуры по наиболее вероятному варианту (с геотермическим градиентом 1,6 градусов на 100 м) максимальная депрессия увеличится, по сравнению с существующим состоянием, в 3,3 раза.
\end{abstract}

Вывод. Полученные результаты указывают на технологическую целесообразность постановки вопроса о переходе на Мутновском геотермальном месторождении к разработке более глубоких горизонтов.

\section{Ключевые слова:}

Геотермальные ресурсы, месторождение, скважина, парлифрт, пласт, максимальная депрессия.

\section{Введение}

Интерес к геотермальным ресурсам на протяжении многих лет характеризуется неуклонным ростом как в исследовательском, так и в практическом аспектах $[1,2]$. Новый импульс в развитии данного направления связан с исследованием и внедрением скважинных теплообменников [3-6], которые в комбинации с тепловыми насосами [7] позволяют использовать геотермальные ресурсы практически в любом месте Земного шара. Однако тепловая мощность таких систем ограничена и в десятки раз уступает мощности скважин, непосредственно выводящих геотермальные флюиды на поверхность. Поэтому скважинные теплообменники - это, прежде всего, неглубокие (и недорогие) скважины и локальные (маломощные) системы. Для масштабных пользователей на ближайшее время наибольше перспективы по-прежнему связываются с эксплуатацией скважин, выводящих геотермальные флюиды на поверхность.

Геотермальные ресурсы, являясь частью георесурсов, в отечественной сфере исследований и разрабо- ток имеют неоднозначную трактовку. Часто данное понятие определяется в неразрывной связи с гидрогеологическими объектами $[8,9]$, фактически исключая из рассмотрения возможность использования энергии сухих пород. Вместе с тем вопросы об использовании энергии сухих горячих пород имеют богатую историю [10] и вызывают непроходящий интеpec [11-13]. В настоящей работе, вслед за [14], под геотермальными ресурсами будет пониматься энергия пород и флюидов в недрах Земли, которая может быть извлечена в форме теплоты для эффективного практического использования.

Обозначившийся в начале текущего века переход к самоокупаемым проектам обуславливает актуальность исследований, направленных на повышение эффективности технологий добычи и использования геотермальных ресурсов [14]. В отечественной практике наибольшей тепловой мощностью характеризуются добычные скважины, работающие в режиме парлифта, осуществляющего подъем флюида из продуктивного пласта за счет пластового давления и об- 
легчения флюида в стволе скважины в результате кипения. При этом скважины, обладающие наибольшей производительностью, находятся на Мутновском геотермальном месторождении, обеспечивающем теплоносителем (паром) работу двух электростанций, вырабатывающих более $80 \%$ всей отечественной электроэнергии на геотермальном теплоносителе.

Разработка Мутновского геотермального месторождения, так же как и аналогичных объектов мира, показала актуальность изучения парлифтной технологии добычи, что способно существенно расширить возможности для повышения эффективности технологий разработки месторождений. Например, существует заблуждение о том, что малый диаметр скважины является одной из причин невозможности ее работы в режиме парлифта [15]. Вместе с тем ранее отечественными исследователями отмечалось, что, напротив, завышенный диаметр может служить причиной неспособности скважины к работе [16]. Детальное исследование этого вопроса позволило обосновать и с успехом внедрить способ введения в эксплуатацию скважин, потерявших кондиции, или считавшихся некондиционными, путем уменьшения внутреннего диаметра обсадных колонн [17].

В настоящей работе на примере Мутновского месторождения исследуется возможность повышения эффективности парлифтной добычи геотермального флюида при переходе к освоению более глубоких горизонтов.

\section{Методика оценки эффективности парлифта}

В качестве характеристики подъемной способности парлифта в [18] предложено использовать предельное пластовое давление, соответствующее значению, ниже которого парлифт будет не в состоянии обеспечить подъем глубинного флюида на поверхность, т. е. скважина принципиально не сможет работать на самоизливе за счет парлифта. На основе этого для характеристики эффективности парлифтной добычи предлагается использовать максимальную депрессию в пласте, которую может обеспечить парлифт. Данная величина определяется как разность пластового давления на уровне питания скважины в невозмущенном состоянии (до начала работы) и предельного пластового давления. Следовательно, эта величина определяет принципиальный предел в снижении пластового давления в процессе эксплуатации. Кроме того, поскольку депрессия в пласте, создаваемая на забое скважин, имеет непосредственную связь с расходом добываемого флюида, предложенная величина может быть использована для оценки максимального расхода, который может быть достигнут парлифтной добычей в данных условиях. Причем в этом случае под максимальным расходом следует понимать не расход одиночной скважины, имеющей ограниченную пропускную способность, а расход, который может быть достигнут группой скважин, создающих депрессию в пласте.

На рис. 1 представлена характеристика типовой скважины Мутновского месторождения, отражающая зависимость забойного давления (для исключения необходимости детализации условий течения в области питания, обычно являющейся неразрешимой задачей, под забойным давлением принимается давление на уровне верхней границы области питания) от расхода (линия 1). Параметры скважины: общая глубина 2000 м, глубина до области питания 1400 м, внутренний диаметр до глубины 1100 м - 0,225 м, в интервале 1100-1400 м - 0,152 м, энтальпия флюида 1200 кДж/кг, устьевое давление 7 бар (принимается постоянным). Расчет давления в скважине на уровне верхней границы области питания проводился с помощью программы WELL-4 [19]. Предельное пластовое давление определяется точкой экстремума на данной характеристике (27 бар). На рис. 1 также обозначен уровень давления в типовой скважине на верхней границе области питания в невозмущенном состоянии (70 бар). Таким образом, максимальная депрессия в пласте, которую может обеспечить парлифт, в данном случае составляет 43 бара.

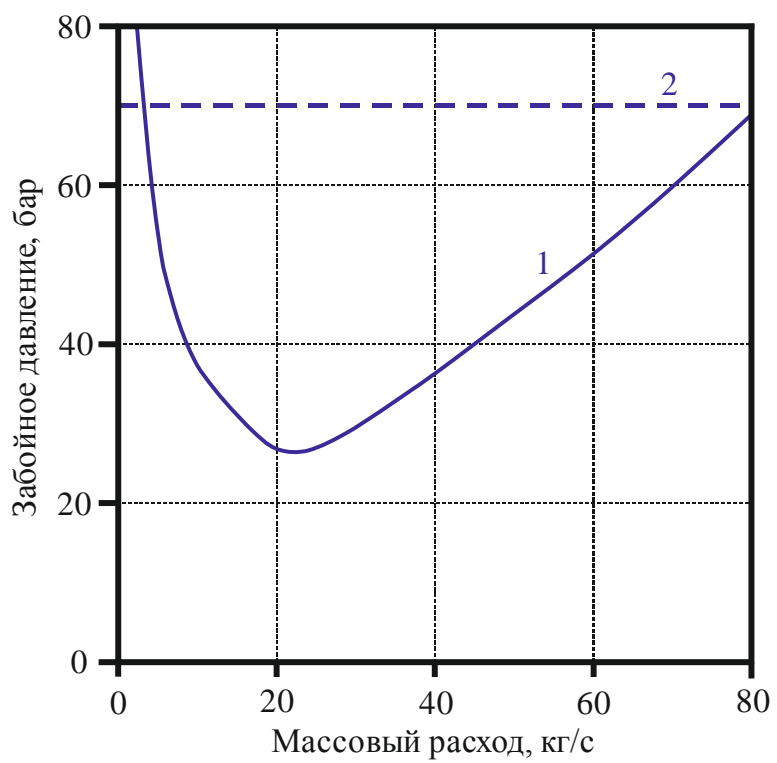

Pис. 1. Характеристика типовой скважинь Мутновского месторождения (кривая 1) и уровень невозмущенного давления на верхней границе области питания (линия 2)

Fig. 1. Characteristics of a typical well of the Mutnovskoe field (curve 1) and the level of undisturbed pressure at the upper boundary of the feed area (line 2)

\section{Оценка максимальной депрессии в пласте при переходе к освоению глубоких горизонтов Мутновского месторождения}

Согласно имеющимся данным, Мутновское геотермальное месторождение по типу резервуара относится к классу вододоминирующих. Продуктивный пласт месторождения, исключая некоторые близповерхностные паровые «шапки», содержит однофазный флюид (воду), включает многочисленные продуктивные зоны и имеет субвертикальное расположение. В настоящее время разработка месторождения осуществляется скважинами, имеющими глубину до 2 км, вскрывающими продуктивные зоны в диапазоне глубин от 1 до 2 км. 
Существенной проблемой разработки месторождения является падение пластового давления ниже предельных значений для устойчивой работы парлифта, что приводит к самозадавливанию добычных скважин и выводу их из эксплуатации. На рис. 2 приведена динамика пластового давления по измерениям в скважине Гео-4 на глубине 1400 м. Скважина находилась в эксплуатации, измерения проводились во время плановых остановов, а в 2018 г. была выведена из эксплуатации.

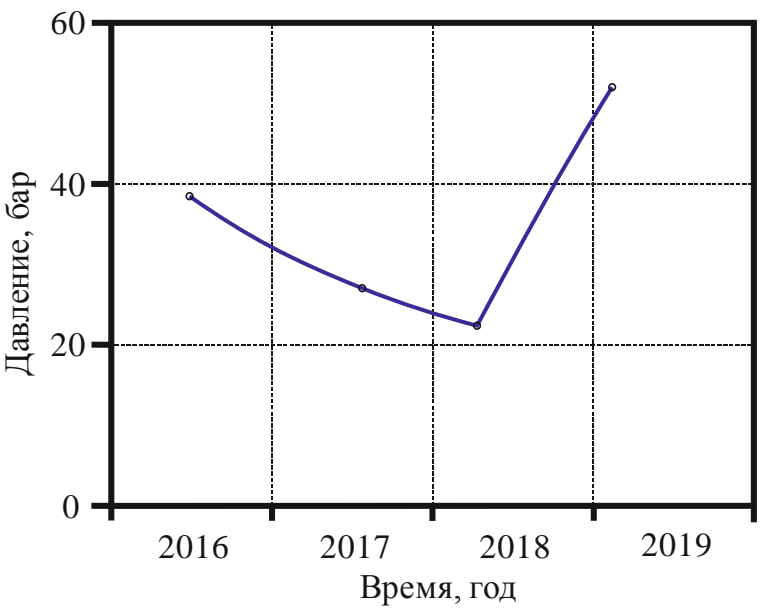

Pис. 2. Изменение давления в скважине Гео-4 на глубине $1400_{\mathrm{M}}$

Fig. 2. Pressure change in well Geo-4 at a depth of $1400 \mathrm{~m}$

Как видно из рисунка, давление в пласте в процессе эксплуатации снизилось до значений, менее предельных для ранее рассмотренного примера с типовой скважиной. Отметим, что скважина Гео-4 характеризуется энтальпией, превышающей расчетную для типовой скважины, что снижает предельное пластовое давление [18] по отношению к типовой скважине.

Учитывая данную проблему, в настоящее время организацией, эксплуатирующей месторождение (Филиал ПАО «Камчатскэнерго» Возобновляемая энергетика), рассматривается вопрос о переходе к разработке более глубоких горизонтов скважинами, глубиной 3 и 4 км. Предполагается, что такое решение повысит эффективность парлифта, т. е. увеличит максимальную депрессию, создаваемую скважинами.

Рассмотрим конкретные предложения по переходу к разработке более глубоких горизонтов - скважины 3 и 4 км. Для скважины глубиной 3 км примем конструкцию: глубина до области питания 2400 м, внутренний диаметр от устья до глубины 1000 м 0,302 м, в интервале 1000-1900 м - 0,225 м, от 1900 м до забоя - 0,152 м. Для скважины глубиной 4 км примем конструкцию: глубина от устья до области питания 3400 м, внутренний диаметр до глубины 1200 м 0,302 м, в интервале $1200-2600$ м - 0,225 м, от 2600 м до забоя $-0,152 \mathrm{м}$.

В отношении температуры, а следовательно, и энтальпии флюида на рассматриваемых глубинах имеются различные мнения, основанные на результатах математического моделирования геотермального ре- зервуара, - увеличение температуры [20, 21], снижение температуры [22]. Отметим, что результаты математического моделирования имеют связь с качеством и объемом исходных данных. Авторы настоящей работы располагают полным набором данных натурных исследований на месторождении, в отличие от авторов указанных работ, имевших ограниченный доступ к таким данным. При отсутствии прямых измерений температур на рассматриваемых глубинах текущее состояние исследований показывает, что не следует ожидать снижения температуры с глубиной. С учетом этого расчеты для глубоких скважин осуществлялись для двух вариантов: 1) типовое значение энтальпии на устье существующих скважин (1200 кДж/кг), 2) значение, советующего росту температуры в геотермальном резервуаре с геотермическим градиентом 1,6 градусов на 100 м, что соответствует увеличению расчетной энтальпии для скважины 3 км до 1284 кДж/кг, и для скважины 4 км до 1368 кДж/кг.

Результаты расчетов зависимости давления на верхней границе области питания для глубоких скважин представлены на рис. 3, 4. Расчеты выполнялись с помощью программы WELL-4. Во всех случаях устьевое давление принималось постоянным и равным 7 бар. Там же приведены расчетные уровни в невозмущенном состоянии, советующие значению 70 бар на глубине 1400 м, что было принято для типовой скважины. Расчет давления в невозмущенном состоянии осуществлялся с учетом зависимости плотности флюида от температуры. Максимальная депрессия в пласте для скважины 3 км составляет по варианту 1 - 82 бара, по варианту 2 - 96 бар, для скважины 4 км по варианту 1 - 74 бара, по варианту 2 - 143 бара.

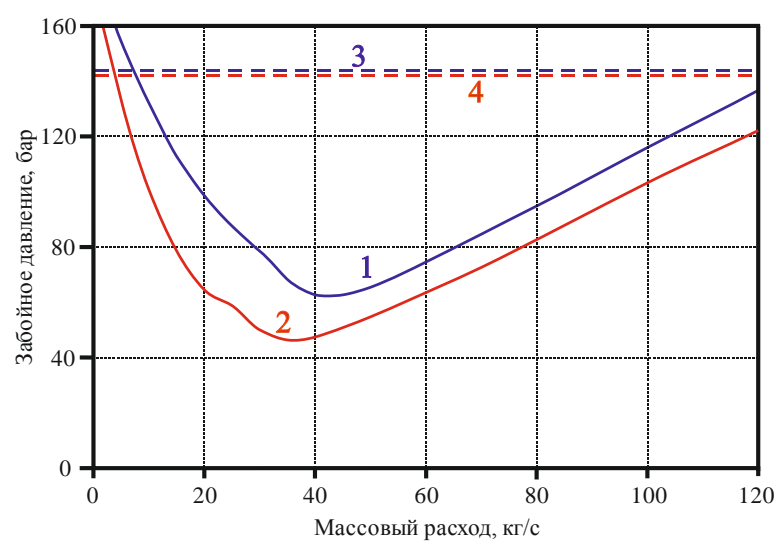

Puc. 3. Зависимость давления на верхней границе области питания (забойного давления) от расхода в скважине 3 км: 1 - вариант 1 (энтальпия 1200 кДж/кг), 2 - вариант 2 (энтальпия 1284 кДж/кг), 3 и 4 - уровни в невозмущенном состоянии по вариантам 1 и 2, соответственно

Fig. 3. Dependence of pressure at the upper boundary of the feed area (bottomhole pressure) on the flow rate in the well $3 \mathrm{~km}: 1$ - option 1 (enthalpy $1200 \mathrm{~kJ} / \mathrm{kg}$ ), 2 - option 2 (enthalpy $1284 \mathrm{~kJ} / \mathrm{kg}$ ), 3 and 4 - levels in undisturbed state according to options 1 and 2, respectively 


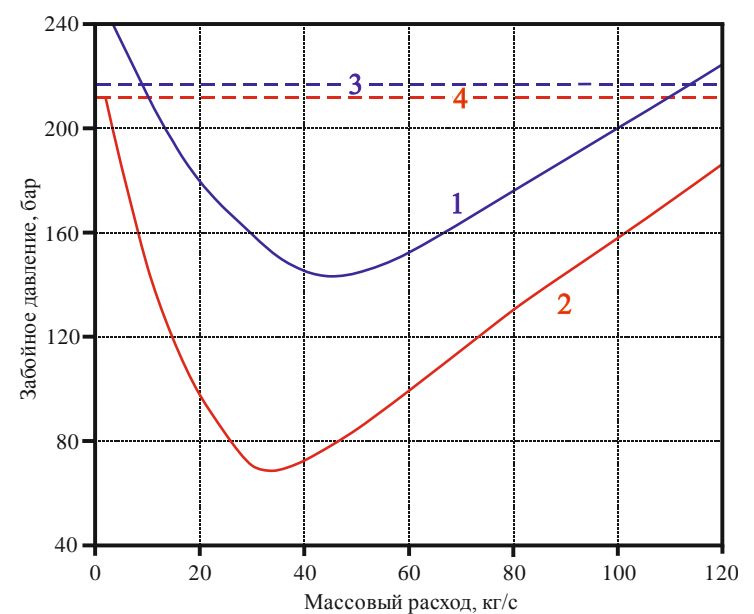

Pис. 4. Зависимость давления на верхней границе области питания (забойного давления) от расхода в скважине 4 км: 1 - вариант 1 (энтальпия 1200 кДж/кг), 2 - вариант 2 (энтальпия 1368 кДж/кг), 3 и 4 - уровни в невозмущенном состоянии по вариантам 1 и 2, соответственно

Fig. 4. Dependence of pressure at the upper boundary of the recharge area (bottomhole pressure) on the flow rate in the $4 \mathrm{~km}$ well: 1 - option 1 (enthalpy $1200 \mathrm{~kJ} / \mathrm{kg}$ ), 2 - option 2 (enthalpy $1368 \mathrm{~kJ} / \mathrm{kg}$ ), 3 and 4 - levels in undisturbed state according to options 1 and 2, respectively

\section{Обсуждение полученных результатов}

Напомним, максимальная депрессия в пласте, которую может обеспечить парлифт в типовой скважине Мутновского месторождения глубиной 2 км составляет 43 бара. При увеличении глубины до 3 км максимальная депрессия вырастает до 82 бар по варианту 1, до 96 бар по варианту 2. То есть приближенно следует ожидать увеличения максимальной депрессии в два раза. Данный эффект достигается увеличением (удлинением) области двухфазного (пароводяного) течения в скважине. Характерные для пароводяного потока градиенты давления существенно ниже гидростатического градиента давления в однофазном (водяном) геотермальном резервуаре. В результате чем больше будет область пароводяного течения в скважине, тем больше будет создаваться депрессия на забое.

Согласно классическим представлениям динамики подземных вод [23], рост депрессии в два раза в условиях стационарной фильтрации увеличивает расход добычи в два раза. Мутновское месторождение является сложным, эволюционирующим в процессе (и в результате) эксплуатации объектом, и стационарность фильтрации в нем может быть принята с большой долей условности. Тем не менее можно однозначно утверждать - переход к освоению горизонтов до 3 км способен существенно повысить эффективность парлифтной добычи, что позволит увеличить как объем добычи, так и срок эксплуатации месторождения.

При увеличении глубины до 4 км максимальная депрессия увеличивается по варианту 1 до 74 бар, по варианту 2 до 143 бар. Следует отметить, что по варианту 1 увеличение депрессии оказалось меньше по сравнению с аналогичным вариантом для скважины 3 км. Как показали расчеты по варианту 1, область двухфазного течения в скважине 4 км не опускается ниже 2450 м, т. е. ниже этой отметки имеет место однофазное (водяное) течение. Дальнейшее увеличение глубины скважины расширяет область однофазного течения, в котором градиенты давления выше гидростатического градиента в резервуаре за счет дополнительного влияния потерь на трение при течении в скважине. Наличие градиентов давления в скважине, превышающих гидростатический градиент давления в резервуаре, негативно отражается на величине создаваемой депрессии.

Если область двухфазного течения распространяется не на всю скважину, ее размер существенно зависит от давления, при котором начинается кипение (давление насыщения), а это давление зависит от начальной температуры воды - чем выше начальная температура воды, тем выше давление насыщения и тем больше область двухфазного течения. Следовательно, если при увеличении глубины температура резервуара не будет возрастать, бурение скважины глубже 3 км не даст положительного эффекта.

Рост температуры воды в резервуаре согласно наиболее вероятному варианту 2 дает увеличение максимальной депрессии в 3,3 раза. Отдельный расчет показал, что даже небольшой рост температуры, соответствующий геотермическому градиенту 0,8 градусов на 100 м, увеличит максимальную депрессию до 121 бара. То есть с высокой долей вероятности можно утверждать, что бурение скважин до 4 км позволит еще больше повысить эффективность разработки месторождения. Окончательный вывод в этом случае можно будет сделать только при получении достоверных данных о температурах в резервуаре на соответствующих глубинах.

Рассматривая вопрос об освоении глубоких горизонтов геотермальных месторождений, необходимо иметь в виду важный аспект - геотермальные ресурсы определяются не только энергией глубинных флюидов, но и энергией вмещающих пород. Увеличение глубины добычных скважин способствует вовлечению в осваиваемые ресурсы большего объема массива пород. Это, так же как и оценка повышения эффективности парлифта, является существенным аргументом в пользу перехода к разработке глубоких горизонтов Мутновского месторождения.

\section{Заключение}

Проведенные исследования показали:

1. Разработка более глубоких горизонтов Мутновского месторождения скважинами до 3 км, при существующей глубине освоения до 2 км, позволит существенно повысить эффективности парлифтной добычи, увеличив максимальную депрессию в пласте, создаваемую добычными скважинами, примерно в два раза.

2. Увеличение глубины освоения Мутновского месторождения до 4 км целесообразно в случае наличия роста температуры резервуара на планируемой к освоению глубине. Так, в случае роста температуры по наиболее вероятному варианту (с 
геотермическим градиентом 1,6 градусов на 100 м) максимальная депрессия увеличится, по сравнению с существующим состоянием, в 3,3 раза.

Полученные результаты, а также возможность увеличения ресурсов месторождения за счет вовлече-

\section{СПИСОК ЛИТЕРАТУРЫ}

1. Bertani R. Geothermal power generation in the world 2010-2014 update report // Geothermics. - 2016. - V. 60. - P. 31-43.

2. Lund J.W., Boyd T.L. Direct utilization of geothermal energy 2015 worldwide review // Geothermics. - 2016. - V. 60. - P. 66-93.

3. Renaud T., Verdin P., Falcone G. Numerical simulation of a deep borehole heat exchanger in the Krafla geothermal system // International Journal of Heat and Mass Transfer. - 2019. V. 143. - № 118496. - P. 1-11.

4. Kayaci N., Demir H. Comparative performance analysis of building foundation Ground heat exchanger // Geothermics. 2020. - V. 83. - № 101710. - P. 1-16.

5. Kumar S., Murugesan K. Optimization of geothermal interaction of a double U-tube borehole heat exchanger for space heating and cooling applications using Taguchi method and utility concept // Geothermics. - 2020. - V. 83. - № 101723. - P. 1-17.

6. Moore K.R., Hollander H.M. Evaluation of $\mathrm{NaCl}$ and $\mathrm{MgCl}_{2}$ hea exchange fluids in a deep binary geothermal system in a sedimentary halite formation // Geothermal Energy. - 2021. - V. 9. - № 8. P. $1-23$.

7. Luo Y., Yan T., Yu J. Integrated analytical modeling of transient heat transfer inside and outside U-tube ground heat exchanger: a new angle from composite-medium method // International Journal of Heat and Mass Transfer. - 2020. - V. 162. - № 120373. - P. 1-16.

8. ГОСТ Р 56909-2016. Нетрадиционные технологии. Геотермальная энергетика. Термины и определения. - М.: Стандартинформ, 2016. - $12 \mathrm{c}$

9. Кирюхин А.В. Геотермофлюидомеханика гидротермальных, вулканических и углеводородных систем. - СПб.: Эко-Вектор Ай-Пи, 2020. - 431 с.

10. Дядькин Ю.Д. Разработка геотермальных месторождений. М.: Недра, 1989. -229 c.

11. Numerical evaluation of hot dry rock reservoir through stimulation and heat extraction using a three-dimensional anisotropic coupled THM model / J. Liao, Z. Hou, M. Haris, Y. Tao, Y. Xie, Y. Yue // Geothermics. - 2020. - V. 83. - № 101729. - P. 1-1.

12. Geologic setting of the potential EGS site at the Gonghe Basin, China: suitability for research and demonstration of Hot Dry Rock geothermal energy development / T. Xu, X. Liang, B. Feng, Z. Jiang // Proceedings, 44th Workshop on Geothermal Reservoir Engineering, Stanford University. - Stanford, California, 2019. $6 \mathrm{p}$.

Информация об авторах

Шулюпин А.Н., доктор технических наук, директор Института горного дела ДВО РАН.

Любин А.А., директор Филиала ПАО «Камчатскэнерго» Возобновляемая энергетика.

Чернев И.И., кандидат технических наук, заместитель главного инженера Филиала ПАО «Камчатскэнерго» Возобновляемая энергетика. ния в разработку энергии большего объема массива вмещающих пород обосновывают технологическую целесообразность постановки вопроса о переходе к разработке более глубоких горизонтов на Мутновском месторождении.

13. Zhang Y., Feng J., Wu X. Analysis of HDR resources development potential in North China // Proceedings, 44th Workshop on Geothermal Reservoir Engineering, Stanford University. - Stanford, California, 2019. - $6 \mathrm{p}$.

14. Шулюпин А.Н., Варламова Н.Н. Современные тенденции в освоении геотермальных ресурсов // Георесурсы. - 2020. T. 22. - № 4. - C. 113-122.

15. Mubarok M.H., Zarrouk S.J. Discharge stimulation of geothermal wells: overview and analysis // Geothermics. - 2017. - V. 70. P. 17-37.

16. Паужетские горячие воды на Камчатке / под ред. В.И. Пийпа. М.: Наука, 1965. - 208 с.

17. Shulyupin A.N., Chernev I.I. Some methods for reducing of steam deficit at geothermal power plants exploitation: Experience of Kamchatka (Russia) // Geothermal Energy. - 2015. - V. 3. № 23. - P. 1-11.

18. Васянович Ю.А., Шулюпин А.Н., Варламова Н.Н. Оценка предельного пластового давления для парлифтной добычи флюида на Мутновском геотермальном месторождении // Горный информационно-аналитический бюллетень. - 2019. № 8. - Спец. вып. 30: Проблемы освоения георесурсов Дальнего Востока. - С. 25-32.

19. Шулюпин А.Н., Чермошенцева А.А. Семейство математических моделей WELL-4 для расчета течений в пароводяных геотермальных скважинах // Математическое моделирование. - 2016. - Т. 28. - № 7. - С. 56-64.

20. Пашкевич Р.И. Научно-техническое обоснование рациональных параметров теплопереноса и фильтрации двухфазного теплоносителя при освоении геотермальных месторождений Камчатки: автореф. дис. ... д-ра техн. наук. - Хабаровск, 2009. -39 c

21. Кирюхин А.В., Сугробов В.М. Геотермальные ресурсы Камчатки и ближайшие перспективы их освоения // Вулканология и сейсмология. -2019 . - № 6. - С. 50-65.

22. Поляков А.Ю. Анализ условий водного и газового питания Мутновского геотермального резервуара (Камчатка): автореф. дис. ... канд. техн. наук. - СПб., 2018. - 24 с.

23. Мироненко В.А. Динамика подземных вод. - М.: Горная книга, 2009. -519 c.

Поступила 18.08.2021 2. 
UDC 622.06

\title{
ASSESSMENT OF THE EFFICIENCY OF STEAM-LITE FLUID PRODUCTION AT THE MUTNOVSKOE GEOTHERMAL FIELD (KAMCHATKA) IN THE DEVELOPMENT OF DEEP HORIZONS
}

\author{
Aleksandr N. Shulyupin', \\ ans714@mail.ru \\ Aleksey A. Lyubin², \\ Lyubin-AA@kamenergo.ru \\ Ivan I. Chernev², \\ Chernev-II@kamenergo.ru \\ 1 Mining Institute of the Far Eastern Branch of the Russian Academy of Sciences, \\ 51, Turgenev street, Khabarovsk, 680000, Russia. \\ 2 Renewable Energy Branch of Kamchatskenergo, \\ 60, Academician Korolev street, Petropavlovsk-Kamchatsky, 680009, Russia.
}

The relevance of the research is caused by the need to expand the resource base of the Mutnovskoe geothermal field (Kamchatka) in order to fill the heat carrier deficit at existing geothermal power plants and increase the capacity of the plants.

The main aim of the research is to assess the efficiency of steam-lite fluid production at the Mutnovskoe geothermal field (Kamchatka) in the development of deep horizons (by wells having deep of 3 and $4 \mathrm{~km}$ at existing developing deep of $2 \mathrm{~km}$ ).

Methods: theoretical substantiation of the efficiency indicator for steam-lift production of geothermal fluid; mathematical modeling of the flow in a production steam-lift well with the existing typical design (2 km deep), as well as in wells planned for drilling with depth of 3 and $4 \mathrm{~km}$; analysis of simulation results.

Results. The use of the maximum depression in the reservoir, which can be provided by the steam-lift technology of production, was substantiated as an indicator of the steam-lift efficiency; it was found that the development of deeper horizons of the Mutnovskoe field with wells up to $3 \mathrm{~km}$, with the existing development depth of up to $2 \mathrm{~km}$, will significantly increase the efficiency of steam-lift production, increasing the maximum drawdown in the reservoir created by production wells by about two times; it was found that the increase in the development depth of the Mutnovskoe field to $4 \mathrm{~km}$ is advisable if there is an increase in the temperature of the reservoir at the depth planned for development, so, in the case of temperature growth according to the most probable option (with a geothermal gradient of 1,6 degrees per $100 \mathrm{~m}$ ), the maximum depression will increase, in cimparison with the existing state, by 3,3 times.

Conclusion. The results obtained indicate the technological feasibility of raising the question of the transition at the Mutnovskoe geothermal field to the development of deeper horizons.

\section{Key words:}

Geothermal resources, field, well, steam-lift, reservoir, maximum depression.

\section{REFERENCES}

1. Bertani R. Geothermal power generation in the world 2010-2014 update report. Geothermics, 2016, vol. 60, pp. 31-43.

2. Lund J.W., Boyd T.L. Direct utilization of geothermal energy 2015 worldwide review. Geothermics, 2016, vol. 60, pp. 66-93.

3. Renaud T., Verdin P., Falcone G. Numerical simulation of a deep borehole heat exchanger in the Krafla geothermal system. International Journal of Heat and Mass Transfer, 2019, vol. 143 , no. 118496 , pp. $1-11$

4. Kayaci N., Demir H. Comparative performance analysis of building foundation Ground heat exchanger. Geothermics, 2020, vol. 83 , no. 101710 , pp. 1-16.

5. Kumar S., Murugesan K. Optimization of geothermal interaction of a double U-tube borehole heat exchanger for space heating and cooling applications using Taguchi method and utility concept. Geothermics, 2020, vol. 83, no. 101723, pp. 1-17.

6. Moore K.R., Hollander H. M. Evaluation of $\mathrm{NaCl}$ and $\mathrm{MgCl} 2$ heat exchange fluids in a deep binary geothermal system in a sedimentary halite formation. Geotherm Energy, 2021, vol. 9, no. 8, pp. 1-23.

7. Luo Y., Yan T., Yu J. Integrated analytical modeling of transient heat transfer inside and outside U-tube ground heat exchanger: a new angle from composite-medium method. International Journal of Heat and Mass Transfer, 2020, vol. 162, no. 120373, pp. 1-16.

8. GOST R 56909-2016. Netraditsionnye tekhnologii. Geotermalnaya energetika. Terminy $i$ opredeleniya [State Standard R 56909-2016. Unconventional technology. Geothermal energy. Terms and definitions]. Moscow, StandardInform Publ., 2016. $12 \mathrm{p}$.

9. Kiryukhin A.V. Geotermoflyuidomekhanika gidrotermalnykh, vulkanicheskikh $i$ uglevodorodnykh sistem [Geothermofluidemechanics of hydrothermal, volcanic and hydrocarbon systems]. St-Petersburg, Eko-Vektor I P Publ., 2020. $431 \mathrm{p}$

10. Dyadkin Yu.D. Razrabotka geotermalnykh mestorozhdeniy [Development of geothermal fields]. Moscow, Nedra Publ., 1989. $229 \mathrm{p}$.

11. Liao J., Hou Z., Haris M., Tao Y., Xie Y., Yue Y. Numerical evaluation of hot dry rock reservoir through stimulation and heat extraction using a three-dimensional anisotropic coupled THM model. Geothermics, 2020, vol. 83, no. 101729, pp. 1-15.

12. Xu T., Liang X., Feng B., Jiang Z. Geologic setting of the potential EGS Site at the Gonghe Basin, China: Suitability for research and demonstration of hot dry rock geothermal energy development. Proceedings, 44th Workshop on Geothermal Reservoir Engineering. Stanford, California, 2019. 6 p.

13. Zhang Y., Feng J., Wu X. Analysis of HDR resources development potential in North China. Proceedings, 44th Workshop on Geothermal Reservoir Engineering. Stanford, California, 2019. $6 \mathrm{p}$

14. Shulyupin A.N., Varlamova N.N. Current trends in the development of geothermal resources. Georesursy $=$ Georesources, 2020, vol. 22, no. 4, pp. 113-122. In Rus.

15. Mubarok M.H., Zarrouk S.J. Discharge stimulation of geothermal wells: overview and analysis. Geothermics, 2017, vol. 70. pp. 17-37. 
16. Pauzhetskie goryachie vody na Kamchatke [Pauzhetka hot waters in Kamchatka]. Ed. by V.I. Piyp. Moscow, Nauka Publ., 1965. $208 \mathrm{p}$.

17. Shulyupin A.N., Chernev I.I. Some methods for reducing of steam deficit at geothermal power plants exploitation: Experience of Kamchatka (Russia). Geothermal Energy, 2015, vol. 3, no. 23, pp. 1-11.

18. Vasyanovich Yu.A., Shulyupin A.N., Varlamova N.N. Assessment of the maximum aquifer pressure for the steam-lift fluid extraction at the Mutnovskoe geothermal field. Mining informational and analytical bulletin, 2019, no. 8, special. vol. 30 (Problems of georesources development of the Far East), pp. 25-32. In Rus.

19. Shulyupin A.N., Chermoshentseva A.A. The collection of mathematical models of WELL-4 for the calculation of flows in steam-water geothermal wells. Mathematical Models and Computer Simulations, 2017, vol. 9, no. 1, pp. 127-132.

20. Pashkevich R.I. Nauchno-tekhnicheskoe obosnovanie ratsionalnykh parametrov teploperenosa i filtratsii dvukhfaznogo teplonositelya pri osvoenii geotermalnykh mestorozhdeniy
Kamchatki. Avtoreferat Dis. Dokt. nauk [Scientific and technical justification for the rational parameters of heat transfer and filtration of two-phase coolant in the development of geothermal fields of Kamchatka. Dr. Diss. Abstract]. Khabarovsk, 2009. 39 p.

21. Kiryukhin A.V., Sugrobov V.M. Geothermal resources of Kamchatka and the immediate prospects of their extraction. Journal of Volcanology and Seismology, 2019, vol. 13, no. 6, pp. 389-402.

22. Polyakov A.Yu. Analiz usloviy vodnogo $i$ gazovogo pitaniya Mutnovskogo geotermalnogo rezervuara (Kamchatka). Avtoreferat Dis. Kand. nauk [Analysis of water and gas supply conditions of the Mutnovsky Geothermal Reservoir (Kamchatka). Cand. Diss. Abstract]. Sankt-Petersburg, 2018. 24 p.

23. Mironenko V.A. Dinamika podzemnykh vod [Groundwater Dynamics]. Moscow, Gornaya Kniga Publ., 2009. 519 p.

Received: 18 August 2021.

\section{Information about the authors}

Aleksandr N. Shulyupin, Dr. Sc., director, Mining Institute of the Far Eastern Branch of the Russian Academy of Sciences.

Aleksey A. Lyubin, director, Renewable Energy Branch of Kamchatskenergo.

Ivan I. Chernev, Cand Sc., deputy chief engineer, Renewable Energy Branch of Kamchatskenergo. 